\title{
MALARIA IN PREGNANCY: EXPERIENCE WITH INTERMITTENT PREVENTIVE TREATMENT IN A UNIVERSITY TEACHING HOSPITAL IN SOUTHERN NIGERIA
}

\author{
${ }^{*}$ Y. Igunma, ${ }^{* *}$ A. Ande, ${ }^{* *}$ M. Ezeanochie, ${ }^{* *}$ K. Hayes
}

*St Georgêิ University of London, Cranmer Terrace, London SW17 0HN, UK, **Department of Obstetrics and Gynaecology, University of Benin Teaching Hospital, Benin City, Edo state,

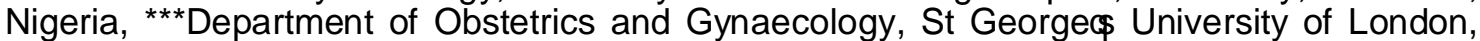
Cranmer Terrace, London SW17 OHN, UK

Correspondence:

Yvonne Igunma

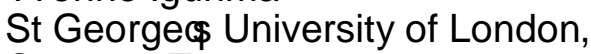

Cranmer Terrace,

London SW17 OHN, UK

E-mail:yvonneig@hotmail.com

\section{INTRODUCTION}

Malaria remains an important public health problem worldwide especially in the tropics and it is an important cause of morbidity in pregnancy. In Nigeria, it is a leading cause of outpatient clinic consultation and is among the three common causes of death in Nigeria. ${ }^{1}$ Malaria in pregnancy can be associated with serious complications for the mother or the developing foetus. The maternal complications include haemolytic anaemia, acute febrile attacks, cerebral malaria, renal failure and maternal mortality. ${ }^{2}$ It can also lead to early pregnancy losses, preterm delivery, low birth weight and intrauterine foetal death. ${ }^{3,4}$

The r̃Roll Back Malariaò initiative was launched as a major initiative in the management of malaria at all health care levels worldwide including Nigeria using evidence based strategies. It recommends environmental vector control (using insecticide treated/ impregnated mosquito nets), prompt and effective case management of malaria using Artemisinin based combination therapy (ACT) and effective malaria chemoprophylaxis in pregnancy using intermittent preventative treatment (IPT). ${ }^{5}$ The use of IPT has been shown to reduce the incidence of anaemia in pregnancy, increase the birth weight of the baby, and reduce the burden of placental malaria, thus leading to better materno-foetal outcomes. ${ }^{4}$

Evidence based recommendations especially when they result in a significant change in practice may not be promptly adopted by care providers or patients. ${ }^{6,7}$ The use IPT for malaria chemoprophylaxis has not been well documented in our environment. The authors of this work expect that the data from this work assist in evaluating compliance with the use of IPT for malaria chemoprophylaxis in pregnancy and the subsequent pregnancy outcome and also assist policy makers/care providers design appropriate strategies to reduce morbidity and mortality associated with malaria in pregnancy.

\section{METHODS}

The study design used was a retrospective study using a cohort of pregnant who received antenatal care at the University of Benin Teaching Hospital, Nigeria. The hospital is referral center serving a population of about 3 million people in the NigerDelta region of Nigeria. All booked women who had antenatal care at UBTH, delivered at UBTH and attended the $6^{\text {th }}$ week post-natal clinic appointment in the Hospital from the $23^{\text {pd }}$ November to the $11^{\text {th }}$ December 2009 were recruited for this study. 
The information of interest collected from case notes included their ante-natal history including the use of malarial chemoprophylaxis and treatment for malaria during pregnancy. In addition, the outcome of labour and materno-foetal outcome were also evaluated. Data collected was entered into a data extraction form designed for the study from the case notes of patients after they had presented at their sixth week appointment for the post natal clinic.

A database was generated and analysed using SPSS version 16 (SPSS, Chicago, IL, USA) for Windows. Data was expressed as percentages, means, and standard deviations for categorical and continuous variables respectively. The differences in proportion were evaluated using Chi-square test for categorical variables and the t test for continuous variables. Statistical significance was set at $p$ value $<0.05$.

\section{RESULT}

Data used in this study was collected from one hundred and five (105) women from the University of Benin Teaching Hospital, Benin City, Nigeria. The demographics and clinical characteristics of the study population are shown in Table I.

The mean age of the women in this study was (Mean $\pm S D$ ) $30.8 \pm 4.5$ years. Of the one hundred and five women, 47 women (44.8\%) were primiparous, $53(50.5 \%)$ were multiparous and 5 $(4.8 \%)$ were grandmultiparous. Most $(66.6 \%)$ of the women in the study were of a post-secondary level of education, which included qualifications such as HND, BSc, MSc and MBBS. Five patients $(4.8 \%)$ had a primary level of education, and 30 $(28.6 \%)$ patients had only reached a secondary level of education, specifically a senior secondary school examination (SSCE).

The retroviral disease status of each patient enrolled in the study was collected, and it was found that 93 $(88.6 \%)$ of the patients were confirmed negative for the disease, while 7 $(6.6 \%)$ patients had a positive diagnosis of HIV and $5(4.8 \%)$ patients did not have their HIV status indicated in the case notes.

In the majority of the patients $(61.9 \%)$ who had their packed cell volume (PCV) determined at booking, results revealed that they were not anaemic, and no patient presented with a PCV of O24\%. The most common presenting gestational age of women at booking was at 11-20 weeks $(46.7 \%)$ and $21-30$ weeks (30.5\%).

Table I: Clinical characteristics of study population

$\begin{array}{lc}\text { Variables } & \begin{array}{c}\text { Number } \\ (\%)\end{array} \\ \text { Mean Age (Mean } \pm \text { SD) years } & 30.8 \pm 4.5 \\ \text { No. of women }<20 \text { years } & 0(0 \%) \\ \text { No. of women 20-35 years } & 89(84.8 \%) \\ \text { No. of women }>35 \text { years } & 16(15.2 \%)\end{array}$

$\begin{array}{lc}\text { Parity } & \\ \text { Primiparous women } & 47(44.8 \%) \\ \text { Multiparous women } & 53(50.5 \%) \\ \text { Grandmultiparous women } & 5(4.8 \%)\end{array}$

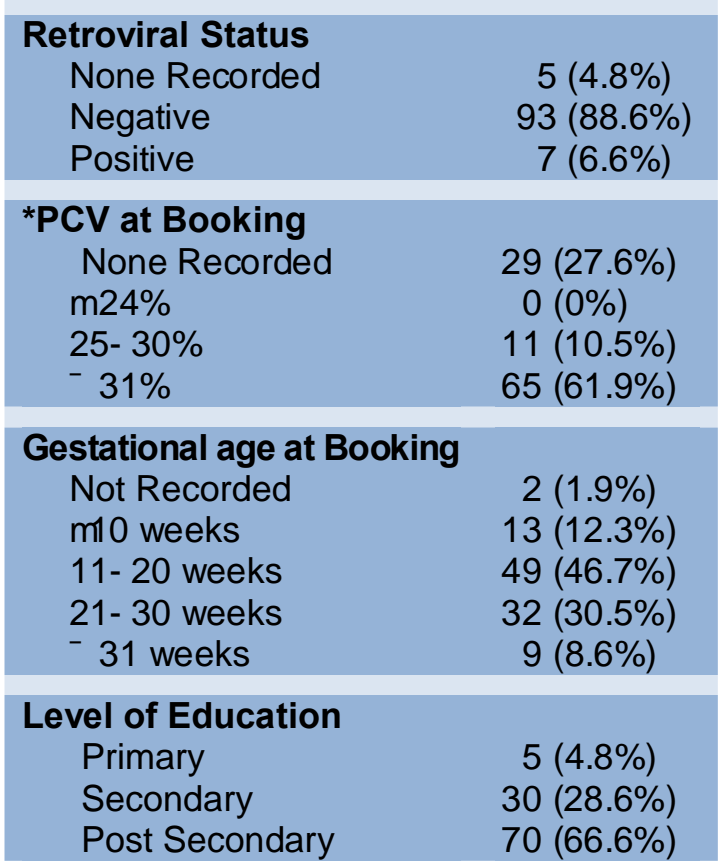

${ }^{*} \mathrm{PCV}=$ packed cell volume

In Table II, the outcome of pregnancy among the study population 
is shown. The mean number of doses of chemoprophylaxis given as intermittent malarial treatment (IPT) was $1.4 \pm 0.6$ (Mean \pm SD) while 20 patients (19.1\%) were not given chemoprophylaxis with IPT.

The prevalence of women amongst the study group with anaemia in pregnancy was very low $(1.9 \%)$, as only 2 patients were clinically diagnosed with it, whilst there was a high prevalence $(41 \%)$ of women in this study with malaria parasitaemia in pregnancy.

The most frequent $(53.4 \%)$ period of malarial parasitaemia amongst the study group was in the late the third trimester, from thirty one weeks.

Table II: Outcome of pregnancy in study population

\begin{tabular}{|c|c|}
\hline Variables & Results \\
\hline $\begin{array}{l}\text { Mean No. of doses of IPT administered (Mean } \pm \text { SD) } \\
\text { None } \\
1 \\
2 \\
3\end{array}$ & $\begin{array}{c}1.4 \pm 0.6 \\
20(19 \%) \\
33(31.4 \%) \\
43(41 \%) \\
9(8.6 \%)\end{array}$ \\
\hline Prevalence of women with Anaemia in Pregnancy & $2 / 105(1.9 \%)$ \\
\hline $\begin{array}{l}\text { Prevalence of women with Malaria Parasitaemia in } \\
\text { Pregnancy }\end{array}$ & $43 / 105(41 \%)$ \\
\hline $\begin{array}{l}\text { Mean Gestational Age in weeks of Malarial Parasitaemia } \\
\text { in Pregnancy (Mean } \pm \text { SD) } \\
\text { Ò10 weeks } \\
11 \text { ï } 20 \text { weeks } \\
21 \text { - } 30 \text { weeks } \\
\text { Ó1 weeks }\end{array}$ & $\begin{array}{l}14.5 \pm 13.5 \\
3(5.2 \%) \\
4(6.9 \%) \\
20(34.5 \%) \\
31(53.4 \%)\end{array}$ \\
\hline Number of Patients Admitted for Malaria in Pregnancy & $2 / 43(4.7 \%)$ \\
\hline $\begin{array}{l}\text { Gestational Age at Delivery } \\
24 \text { ï } 32 \text { weeks } \\
33 \text { ï } 40 \text { weeks } \\
\text { Ó41 weeks }\end{array}$ & $\begin{array}{c}1(1 \%) \\
86(81.9 \%) \\
18(17.1 \%)\end{array}$ \\
\hline $\begin{array}{l}\text { Route of Delivery } \\
\text { Vaginal Delivery } \\
\text { Caesarean Section }\end{array}$ & $\begin{array}{l}74(70.5 \%) \\
31(29.5 \%)\end{array}$ \\
\hline
\end{tabular}

The most frequent $(53.4 \%)$ period of malarial parasitaemia amongst the study group was in the late the third trimester, from thirty one weeks (figure 1). 


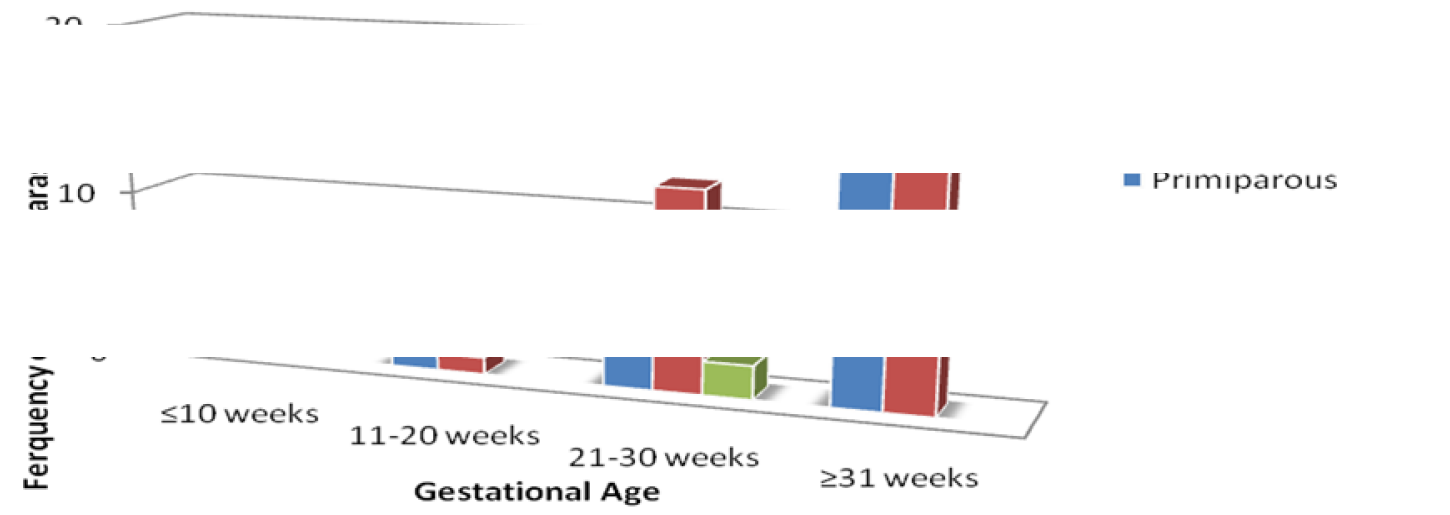

Figure 1: Relationship between malaria parasitaemia at different gestational age and parity group

The mean birth weight (Mean $\pm S D$ ) was $3.2 \pm 0.5$ kilograms with most $(87.7 \%)$ of the babies born with a normal birth weight within the range of $2.5-3.9 \mathrm{~kg}$, whilst $6.6 \%$ of the babies born had low birth weights of less than $2.5 \mathrm{~kg}$. There were a total number of 106 babies born to 105 women (one mother had a twin pregnancy).

Table III: Foetal Outcome among the study population

\begin{tabular}{|c|c|}
\hline Variables & Results \\
\hline $\begin{array}{l}\text { Mean Birth Weight } \\
\text { (Mean } \pm \text { SD) } \\
<2.5 \mathrm{~kg} \\
2.5 i ̈ 3.9 \mathrm{~kg} \\
\text { O4.0kg }\end{array}$ & $\begin{array}{c}3.2 \pm 0.5 \\
7(6.6 \%) \\
93(87.7 \%) \\
6(5.7 \%)\end{array}$ \\
\hline $\begin{array}{l}\text { Sex } \\
\quad \text { Male } \\
\text { Female }\end{array}$ & $\begin{array}{l}49(46.2 \%) \\
57(53.8 \%)\end{array}$ \\
\hline $\begin{array}{l}1^{\text {st }} \text { Minute APGAR score } \\
\text { (Mean) } \\
5^{\text {th }} \text { Minute APGAR score } \\
\text { (Mean) }\end{array}$ & $\begin{array}{l}7.3 \\
8.7\end{array}$ \\
\hline
\end{tabular}

\section{DISCUSSION}

In this study, about half of the study population were primiparous women (never delivered before) who are more vulnerable to malaria in pregnancy compared to multiparous women (one or more previous deliveries) ${ }^{8}$ In addition, about $60 \%$ of the study population registered for antenatal care before 20 weeks gestational age. This is important because it reenforces the need for optimum chemoprophylaxis against malaria in pregnancy as a substantial amount of pregnant women who are vulnerable to malaria present for antenatal care at a relatively early gestational age in pregnancy (after quickening, usually between 16-20 weeks) when IPT can be administered with good effect.

Although more than $80 \%$ of the women received IPT with about half getting two or three doses during pregnancy, about one-fifth of the study population were not documented to have received IPT. This could have adverse implications from a public health perspective with respect to curtailing the impact of malaria in pregnancy. However, since this was a retrospective study using hospital records, it is possible this could be due to improper documentation and record keeping and some patients who are allergic to sulphonamides (present in the Sulphadoxine-pyrimethamine antimalarial drug combination used for IPT) may have used alternative drugs for chemoprophylaxis. The widespread 
administration of IPT among a majority of the study population may partly account for the low prevalence of anaemia and hospitalisation for clinical malaria during pregnancy.

Out of the 57 women who had malaria parasitaemia during pregnancy, about more than half occurred after 30 weeks gestation. In addition, more than four-fifth of malaria parasitaemia occurred after 20 weeks of pregnancy compared with less than 15\% before twenty weeks gestation. This highlights the increasing vulnerability of pregnant women to malaria as pregnancy advances and the value of having the first contact with between pregnant women and health care facilities early in pregnancy. Furthermore, the initiation of chemoprophylaxis from early pregnancy becomes even more relevant to reduce the complications that may be associated with malaria in pregnancy. ${ }^{1,2}$

The overall satisfactory maternal, foetal and perinatal outcome can be considered a reflection of the quality of care available in the facility. However, the findings from the study need to be interpreted with caution. It was a retrospective study in design which makes it prone to problems peculiar with such a study design including suboptimal data entry. In addition, the relatively small sample population and the use of only patients attending a University Teaching Hospital in a country without universal access to antenatal care, home delivery and ignorance is widespread $^{9}$ limits the extrapolation of the results to the general population. However, the study is still very relevant as it provides local data on the use and benefits of IPT, an important strategy for reducing malaria in pregnancy which is a component of the millennium development goal 6 .
In conclusion, the findings from the study reveal that it is feasible to use Sulphadoxine-pyrimethamine as IPT for malaria chemoprophylaxis among pregnant women receiving antenatal care at UBTH. Pregnant women should have first contact in pregnancy with health care facilities at an early gestational age when IPT can be administered effectively to reduce the impact of malaria in pregnancy. This information is important for health workers providing care to pregnant women in malaria endemic regions and to reduce the adverse impact of malaria on foetal outcome.

\section{REFERENCES}

1. Okpere E. Malaria in Pregnancy. In E. Okpere (ed). Clinical Obstetrics (pp. 56-61). Uniben Press, Benin City. 2003:56-61.

2. Lawson, J., \& Stewart, D. (1981). Malaria and Pregnancy. In Obstetrics and Gynaecology in the Tropics and Developing Countries . Edward Arnold, London. 1981:(5972).

3. Barros FC, Bhutta ZA, Batra M, Hansen TN, Victora CG, Rubens CE et al. Global report on preterm birth and stillbirth (3 of 7): evidence for effectiveness of interventions. BMC Pregnancy Childbirth. 2010;(23)10 Suppl 1:S3.

4. Gómez E, López E, Ache A. [Malaria and pregnancy. San Isidro parish, municipality Sifontes, state of Bolívar, Venezuela, 2005-2006. Invest Clin. 2009 Dec;50(4):455-64.

5. World Health Organization. A Strategic Framework for Malaria Prevention and Control During Pregnancy in the African Region. Brazzaville: WHO Regional Office for Africa, 2004. 
6. Hayes SM, Murray $S$, Dupuis $M$, Dawes M, Hawes IA, Barkun AN. Barriers to the implementation of practice guidelines in managing patients with nonvariceal upper gastrointestinal bleeding: $A$ qualitative approach. Can J Gastroenterol. 2010;24(5):289-96.

7. Davis AD, Taylor-Vaisey A. Translating guidelines into practice: A systematic review of theoretic concepts, practical experience and research evidence in the adoption of clinical practice guidelines. Can Med Assoc J 1997;157:408-16
8. Alusala DN, Estambale BB. Intermittent presumptive treatment of malaria to prevent low birth weight in newborns in a cohort of pregnant women from a malaria endemic area. East Afr Med J. 2009; 86(8):378-86.

9. National Population Commission (NPC) [Nigeria] and ICF Macro. Nigeria Demographic and Health Survey 2008. Abuja, Nigeria: National Population Commission and ICF Macro. 2009. 